\title{
A Voltage-Based Approach for Series High Impedance Fault Detection and Location in Distribution Systems Using Smart Meters
}

\author{
Francinei L. Vieira ${ }^{1}{ }^{1}$, Pedro H. M. Santos ${ }^{1, *}$, José M. Carvalho Filho ${ }^{1}$, Roberto C. Leborgne ${ }^{2}$ \\ and Marino P. Leite ${ }^{1}$ \\ 1 Instituto de Sistemas Elétricos e Energia, Universidade Federal de Itajubá, Av. BPS 1303, \\ Itajubá 37500-903, Brazil \\ 2 Universidade Federal do Rio Grande do Sul, Av. Osvaldo Aranha 99, Porto Alegre 90035-190, Brazil \\ * Correspondence: phmdsantos@gmail.com
}

Received: 29 May 2019; Accepted: 28 June 2019; Published: 6 August 2019

\begin{abstract}
High impedance faults (HIFs) have been a major concern for protecting distribution systems and public safety hazards when involving downed conductors. The deployment of smarter grids brings new technologies for smart monitoring, automation, and protection of distribution networks. This paper presents a new method for a series of HIF detection and location in primary distribution feeders, using voltage unbalance measurements collected from smart meters (SMs) installed at low-voltage end-users. The methodology was tested in MATLAB and Simulink through steady-state simulations of a typical $13.8 \mathrm{kV}$ distribution system, under load unbalance and different fault scenarios. Results show that the proposed method is robust and accurate for the detection of blown fuses and broken conductors, with or without ground faults, located either at the source or the load-side. The ease of implementation in SM design, formulation of parameters, and reliable simulation results show potential real-life applications.
\end{abstract}

Keywords: high impedance fault; fault location; distribution network; smart meters; voltage unbalance

\section{Introduction}

The power sector is going through deep changes, both in structure and business models, leading to a higher competitive environment. It is expected of utilities to promote bigger investments in the planning and operation of power systems, aiming for a more sustainable, reliable, and safer energy supply for customers, accompanied by a fast return of the investments.

Utilities, equipment manufacturers, and researchers of the power sector are encouraged to find solutions to mitigate the number and duration of power outages. Improvements in mitigation techniques should be conceived by integrated systems, for example, based on new methods for reliable data acquisition and prompt processing.

A specific class of abnormalities in electrical networks is the high impedance fault (HIF), which presents great difficulties to trip traditional overcurrent protection relays and fuses in primary conductors of distribution networks [1]. Power conductors in unwanted contact with poorly conductive surfaces and tree branches are potential causes for HIFs. Also, a HIF does not need to include a path to the ground, for example, in broken conductors or when there are failures caused by dirty insulators [2,3]. High voltages in downed conductors and electric arcs associated with HIFs are major concerns for public safety and industrial installations and are a possible trigger for wildfires, which may cause legal liabilities, property damage, or human loss [3-5]. Therefore, the quick detection and location of HIFs is critical for utilities and society. 
The low short-circuit current of HIFs and other electrical characteristics that present random behavior, such as harmonics, arcing intermittence, current asymmetry, and non-linearity increase the difficulty of their detection, so new alternatives are often discussed. There have been good up-to-date articles reviewing the existing models and detection techniques for HIFs [5,6], along with insights for further development with emerging technologies. Several detection methodologies have been proposed in the literature, such as voltage drop [4], mechanical contact of downed conductors [7], harmonic or interharmonic currents [8-10], wavelet decomposition [11], artificial neural networks (ANNs) [12], adaptive neuro-fuzzy inference, partial discharges on overhead lines [13], online wavelet decision tree algorithms applied to current measurements [14], and hybrid methodologies using two or more joint techniques [15-18]. Many identification algorithms use a combination of signal processing techniques and computational intelligence methods, which may increase the sophistication and cost of such techniques.

Substation based monitoring has low effectivity for HIF detection, limited by a low fault current and a lack of selectivity to isolate the faulted circuit [4]. Visual inspection is a common practice in utilities for fault identification in overhead distribution networks. However, it is a time-consuming technique which affects the duration of poor performance indexes, such as sustained interruptions. In the long run, this delay to identify faults can also deteriorate the performance of power conductors.

These limitations may be avoided with voltage-based measurements distributed along the feeder. One new aspect that may be useful toward improving distribution systems operation is the progress of communication and advanced metering infrastructure, including fault indicators along the feeder, micro phasor measurement units ( $\mu$-PMU) [19], and smart meters, along with real-time access to measurements. Extensive use of monitoring devices on the distribution network may not be cost-effective, but there is an increasing interest in multifunctional applications using smart metering devices for low-voltage (LV) customers, especially for measurement and distribution systems operation [20-23].

A voltage-based approach for HIF location and clearing is not new. In Reference [24], downed or broken conductors were detected by monitoring the zero-sequence component of phase voltages using electric field sensors placed nearby the conductors of the primary feeder, coupled with a communication system based on carrier signals. In Reference [25], a detection method for HIF was proposed considering a positive sequence voltage drop or the percentage of negative and zero sequence voltage drops. Open conductor detectors based on voltage measurements and GSM communication are described [26,27]. For instance, the authors of [26] applied their HIF methodology to the data of measurement units installed in the LV-side of each distribution transformer.

The aim of this paper is to present an alternative method for the detection and location of series HIFs by monitoring the voltage unbalance using smart meters at the LV-side of distribution transformers, with an improved algorithm compared to our preliminary study [28]. This method uses voltage-based measurements, time domain analysis, and a simple threshold to classify a faulty state from a healthy state. It does not need current transformers (CTs), voltage transformers (VTs), or any other equipment to be installed on the grid. It is only necessary to insert an additional calculation function on smart meters and transmit the information to an algorithm on the operator server for analysis. After that, the HIF location is displayed to the power system operator using the system topology along with the electrical position of the transformers. The proposed method was tested by steady-state simulations, in different branches of a typical distribution system. Scenarios include different fault contact impedances, broken conductors dropping at the load-side or source-side, and conductors suspended in the air with no contact.

Compared to previous methodologies proposed in the literature, this method has the advantage of HIF detection and location in primary conductors, using smart meters SMs placed at the LV-side of distribution transformers, sharing the measurement structure of the smart metering device and, thus, avoiding the deployment of new sensors along the feeder. The proposed technique using a voltage unbalance approach has not been widely discussed in the literature for HIF detection or 
location. This paper shows some advantages of using smart meters for HIF detection and location, which can support utilities in better decision making and quick remedial actions in distribution networks. Some of the benefits would be the improvement of the electric performance metrics for the utility and the hazard reduction for humans in situations of downed conductors.

Additionally, a transitory phenomenon caused by arc occurrence with intermittent behavior is typical for HIFs. The voltage unbalance approach proposed for a series HIF detection and location in this paper presents an advantage when dealing with these transitory events, since a situation of open conductors causes a large voltage unbalance, and eventual high frequencies are not expected to decrease it considerably.

The series HIF detection and location method proposed in this paper was initially investigated in [28], comparing the performance of different methods for voltage unbalance calculation. Based on those results, this paper uses the formulation presented in [29-31], which considers only phase-to-phase measurements, different from other formulations that demand the manipulation of symmetrical components. In Reference [28], the location method was presented in an intuitive approach only. The present stage of this research demanded the complete reconstruction and modification of the method presented in Section 2.2, allowing the implementation of an effective algorithm, with a possibility for a real-life operator application. The present method was tested on the same test feeder as [28], although it expands the number of simulation cases.

The paper is organized as follows: Section 2 presents the background and the proposed voltage unbalance method for HIF detection and location. Section 3 presents a case study in a typical distribution network. Section 4 gives the simulation results for different fault scenarios, and Section 5 concludes the paper and lists its contributions.

\section{Proposed Methodology for HIF Detection and Location}

The proposed methodology uses classic concepts of the voltage unbalance theory, with a low digital processing burden on a SM. The detailed steps are portrayed in the following subsections, first focusing on the theory for HIF detection, then on the proposed algorithm for fault location.

\subsection{Detection}

The philosophy of the proposed protection system to detect a HIF is based on the identification of the voltage drop and whether this disturbance takes place at a point upstream or downstream of a meter, allowing the identification and location of a fault [24]. For example, a powered broken conductor causes a "phase failure" in all circuits and loads downstream of the breakpoint, leading to an extreme voltage unbalance.

The method has been tested in different typical HIF scenarios, which are classified in this paper in two main types: Series (with an open conductor situation) and shunt (with an unbroken conductor situation). The shunt faults are characterized by unbroken conductors with unwanted contact with obstacles, such as tree branches. The series faults are characterized by broken conductors and are subclassified as passive (no ground involved), or active (contact to ground at source or load-side). Figure 1 shows (a) passive series faults; (b) active series faults, contact to the source-side; (c) active series faults and contact to load-side; and (d) shunt faults.

Two fundamental methods can be employed to calculate the voltage unbalance. The first method quantifies the unbalance by decomposing the phase voltages into symmetrical components. The unbalance factor $\left(K_{S} \%\right)$ is given by the ratio between the negative sequence voltage $\left(V_{2}\right)$ and the positive sequence voltage $\left(V_{1}\right)[29,32]$, as in (1).

$$
K_{S \%}=\frac{\left|V_{2}\right|}{\left|V_{1}\right|} \cdot 100 \%
$$

A commonly accepted equation, as presented in $[29,30]$, needs only the phase-to-phase fundamental voltage magnitudes, as shown in (2) and (3). This method, initially proposed by the International Council 
for Large Electric Systems (CIGRE), is known as the CIGRE method and demands fewer calculations and offers the same results of (1) [31], being a good alternative to the method of symmetrical components.

$$
\begin{gathered}
K_{\%}=\sqrt{\frac{1-\sqrt{3-6 \beta}}{1+\sqrt{3-6 \beta}}} \cdot 100 \% \\
\beta=\frac{V_{A B}^{4}+V_{B C}^{4}+V_{C A}^{4}}{\left(V_{A B}^{2}+V_{B C}^{2}+V_{C A}^{2}\right)^{2}}
\end{gathered}
$$

where $V_{A B}, V_{B C}$, and $V_{C A}$ are the line voltage magnitudes.

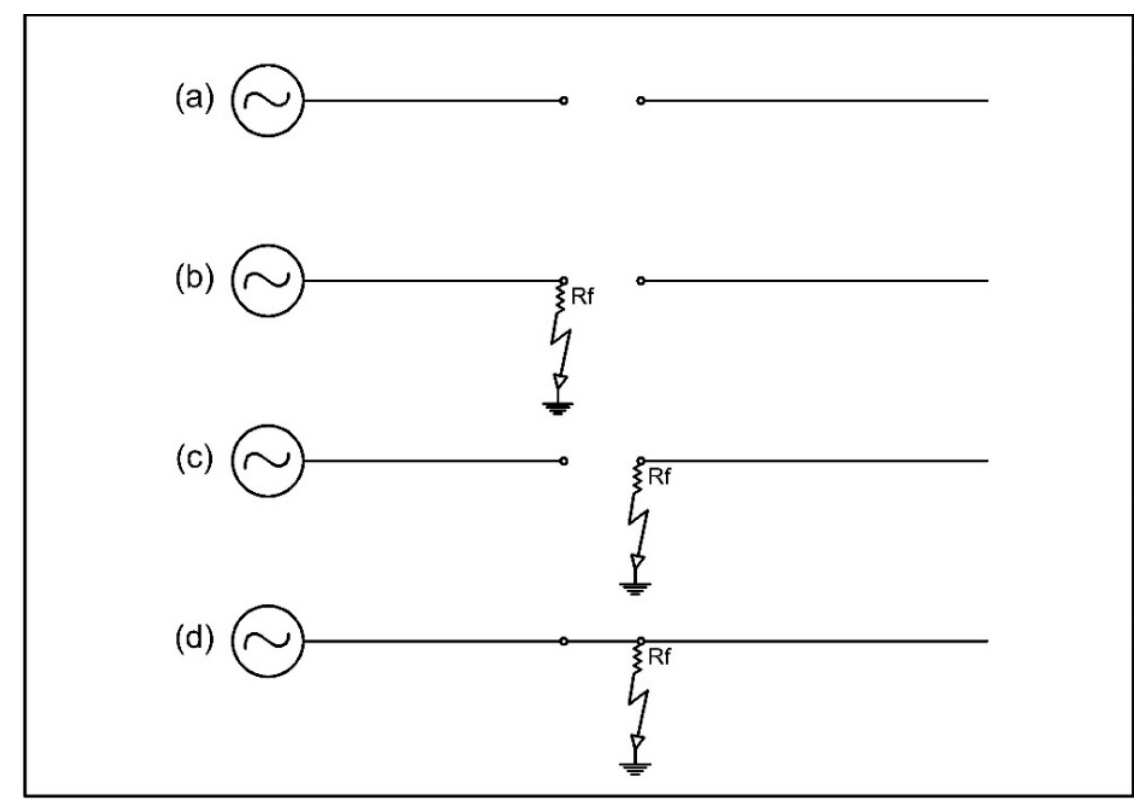

Figure 1. High impedance faults (HIF) types: (a) Passive series fault; (b) downed conductor, contact to the source-side; (c) downed conductor, contact to the load-side; and (d) shunt fault.

Identification of a faulted section of the feeder is based on the unbalance factor $\left(K_{\%}\right)$, when a voltage unbalance threshold is surpassed. This factor is calculated using a new functionality to be implemented in three-phase SM connected to the LV side of distribution transformers. SMs are facing an increasing penetration in consumer units and distributed generators, since it is possible to use some of them for fault identification and location. To make that possible, it will be necessary to insert a new functionality in three-phase SM-the calculation of the voltage unbalance, as shown in Figure 2.

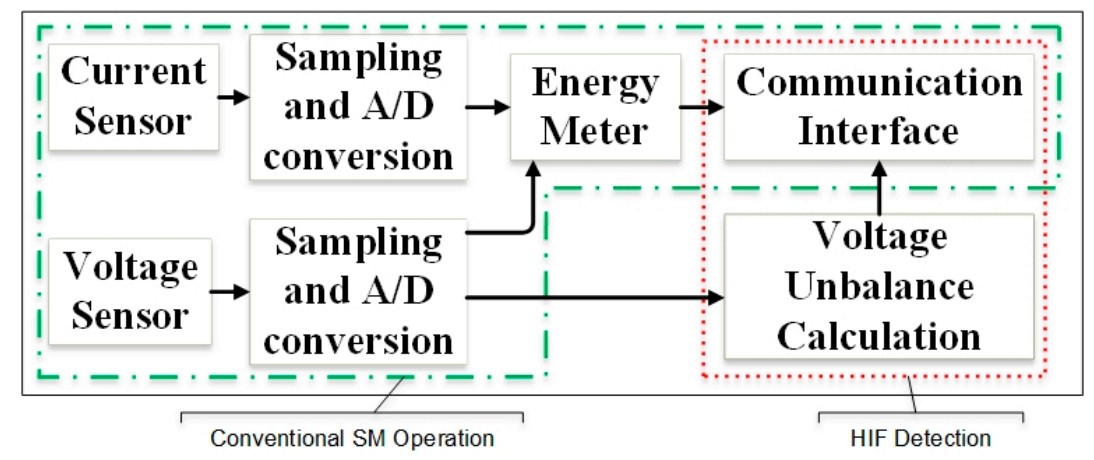

Figure 2. Smart meter (SM) diagram with new functionality for HIF detection. 
This work will apply the formulation in accordance with the Equations (2) and (3). Using smart meters on the LV-side has the advantage of the distribution transformer operating as a voltage transformer, a vital condition to justify a feasible application of this method.

International standards, such as the EN-50160 and IEC 61000-series [29,33-35] specify voltage unbalance limits up to $2 \%$ for LV and medium-voltage (MV) power grids, with an instantaneous limit up to $4 \%$. Preliminary studies performed with unbalanced loads up to $30 \%$ and no phase failure show a maximum unbalance within the limit of $2 \%$ [28]. The authors identified a minimum unbalance around $49 \%$ in the SM installed downstream of the fault location. Therefore, the unbalance threshold may be fixed within a range between $5 \%$ and $49 \%$. The proposal is checking for an unbalance factor higher than $30 \%\left(K_{L I M}\right)$ because this condition is a strong indicator of a HIF in the simulated test feeder. This value can be adjusted by the system operator, according to the system characteristics.

The detection technique is explained using Figure 3, where phase A opened without dropped conductors to the ground, simulating a series fault. The SM is connected at the LV-side of the transformer, and the $\mathrm{K}$ factor on the primary conductors should be correctly inferred by measurements at the LV-side, regardless of the transformer connection. The source is assumed to be balanced and symmetrical. The feeder is $15 \mathrm{~km}$ long, composed by aluminum conductors (4 AWG). An unbalanced Y-connected load is connected to each transformer. Details are given in Table 1.

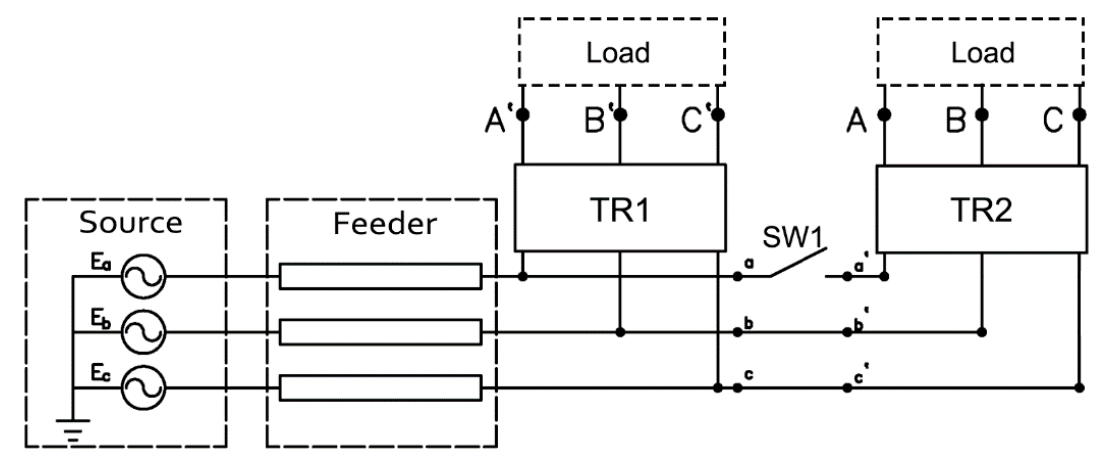

Figure 3. Three-phase feeder diagram with Y-connected loads and an opening at phase A.

Table 1. Parameters of the supply voltage and the loads connected at the LV-side.

\begin{tabular}{cccc}
\hline Source Equivalent & $\mathbf{1 3 . 8 ~ k V}$ & $\mathbf{X} / \mathbf{R}=\mathbf{8}$ & $\mathrm{S}_{\mathrm{CC}}=\mathbf{1 2 0}$ MVA \\
\hline \multicolumn{4}{c}{ Feeder Impedance } \\
\hline Positive sequence $\left(\mathrm{Z}_{1}\right)$ & \multicolumn{3}{c}{$1.6118+\mathrm{j} 0.4637 \Omega / \mathrm{km}$} \\
Zero sequence $\left(\mathrm{Z}_{0}\right)$ & \multicolumn{3}{c}{$4.8354+\mathrm{j} 1.3911 \Omega / \mathrm{km}$} \\
\hline \multicolumn{4}{c}{ Transformers $(\Delta-\mathrm{Y})$} \\
\hline \multicolumn{4}{c}{$45 \mathrm{kVA}$} \\
Nominal power & $13.8 \mathrm{kV}$ & $0.001+\mathrm{j} 15.08 \Omega$ \\
Winding 1 $(\Delta)$ & $220 \mathrm{~V}$ & $0.001+\mathrm{j} 15.08 \Omega$ \\
Winding 2 $(\mathrm{Y})$ & Load (LV-side) \\
\hline \multicolumn{5}{c}{$\mathrm{B}$} \\
\hline Phase & $\mathrm{A}$ & $\mathrm{C}$ \\
Current $(\mathrm{A})$ & 60 & 0.20 & 45 \\
Power factor (lagging) & 0.48 & 0.77 \\
\hline
\end{tabular}

The voltages are measured by a SM in terminals $\mathrm{A}^{\prime}, \mathrm{B}^{\prime}$, and $\mathrm{C}^{\prime}$ for transformer 1 (TR1) and in A, B, and $\mathrm{C}$ for transformer 2 (TR2). They are given in Table 2.

Table 2. Line voltages in the LV-side of transformers.

\begin{tabular}{cccc}
\hline Transformer & $V_{A B}(\mathbf{V})$ & $V_{B C}(\mathbf{V})$ & $V_{C A}(\mathbf{V})$ \\
\hline$T R 1$ & 208.5 & 212.4 & 213.1 \\
$T R 2$ & 173.1 & 189.5 & 28.2 \\
\hline
\end{tabular}


Applying the voltages in (2) and (3) allow the calculation of the voltage unbalance factor of the transformers. TR2 voltages were taken for demonstration in an example in (4) and (5).

$$
\begin{gathered}
\beta_{T R 2}=\frac{173.1^{4}+189.5^{4}+28.2^{4}}{\left(173.1^{2}+189.5^{2}+28.2^{2}\right)^{2}}=0.4923 \\
K_{T R 2}=\sqrt{\frac{1-\sqrt{3-6 \times 0.4923}}{1+\sqrt{3-6 \times 0.4923}}} \cdot 100 \%=80.38 \%
\end{gathered}
$$

In a similar approach, the values $\beta=0.3335$ and the factor $K_{T R 1}=1.58 \%$ were obtained for TR1. Observe that the transformer installed downstream of the fault location (TR2) presented an unbalance factor much higher than $K_{T R 1}$. Those differences are the key point for the fault location algorithm, presented in the following subsection.

\subsection{Location}

The location algorithm is executed at the operator level. Thus, a communication channel it assumed between the SM and the system operator, which allows the operator to read the unbalance factor $K_{\%}$ from the SMs. HIF location algorithm uses two inputs:

- The previous knowledge of the system topology, i.e., every branch between transformers and derivation nodes are listed on a matrix format, mapping the distribution feeder;

- The unbalance factor measurements from each smart meter, identified by its respective MV/LV transformer in the distribution system.

The HIF location algorithm is described below:

1. The location procedure initially reads the voltage unbalance factor $K_{\%}$ for every SM on the system;

2. It identifies distribution transformers, for which the respective SM presents an unbalance factor $K_{\%}$ below the unbalance threshold $\left(K_{\text {LIM }}\right)$;

3. For all SMs with "healthy" results $\left(K_{\%}<K_{L I M}\right)$, the algorithm marks each branch on the respective path from the SM to the substation as "clear";

4. The algorithm identifies distribution transformers, for which the respective SM presents an unbalance factor $K_{\%}$ above $K_{L I M}$, referred here as "unbalanced SM";

5. The algorithm goes through every branch from each "unbalanced SM" to the substation, marking it as "yellow", until it finds a branch marked as "clear".

6. The "yellow" branch immediately before a "clear" branch is the probable location of the HIF, and it is marked as "red".

7. At the end of the process, the algorithm presents the branches marked as "clear", i.e., probably not affected by the HIF; the branches marked as "yellow", i.e., probably affected by the HIF; and, finally, the branch(es) marked as "red", i.e., the probable location of the HIF.

The proposed algorithm is presented in the flowchart in Figure 4.

Given the fact that the $K_{\%}$ factor could not be calculated in scenarios of two or three missing phases, the results show an indeterminacy (IND). Indeterminacy is a strong indicator of HIFs or blown fuses, and is, therefore, interpreted here as a severe voltage unbalance. 


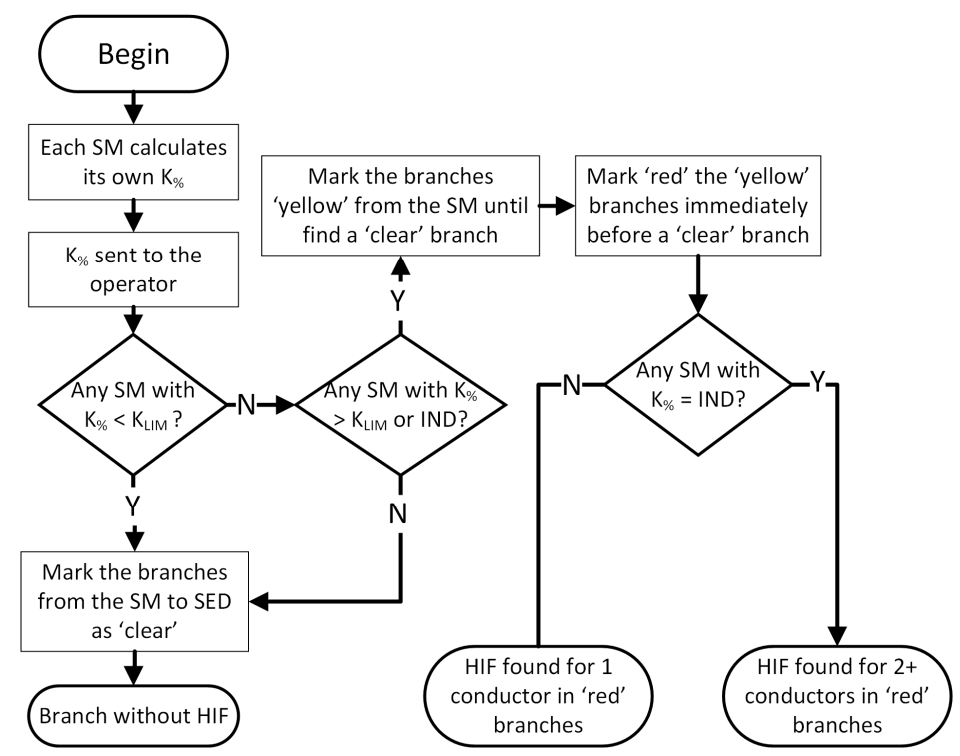

Figure 4. Flowchart of the proposed HIF location algorithm.

\section{Case Study}

The test feeder has eight three-phases, $45 \mathrm{kVA}$, Dyn1 connected, and 50\% loaded distribution transformers. Loads are set up to $30 \%$ unbalance to represent the system unbalance, which is described in Table 3. The medium voltage overhead power lines are single 4/0 AWG aluminum. The distance between each transformer is $1 \mathrm{~km}$, as well as the distance from the substation to the first transformer. A smart meter is considered on the low-voltage side of each transformer, properly connected and communicating to the operator. The test feeder diagram is shown in Figure 5.

Table 3. The load connected to each transformer and its respective current unbalance.

\begin{tabular}{|c|c|c|c|c|c|c|c|c|}
\hline \multirow{2}{*}{ Phase $^{1}$} & \multicolumn{8}{|c|}{ Transformer } \\
\hline & TR1 & TR2 & TR3 & TR4 & TR5 & TR6 & TR7 & TR8 \\
\hline $\mathbf{A}$ & $\begin{array}{c}59.2 \\
\left(-61.4^{\circ}\right)\end{array}$ & $\begin{array}{c}59.2 \\
\left(-1.4^{\circ}\right)\end{array}$ & $\begin{array}{c}59.2 \\
\left(-61.4^{\circ}\right)\end{array}$ & $\begin{array}{c}59.2 \\
\left(-61.4^{\circ}\right)\end{array}$ & $\begin{array}{c}45.4 \\
\left(-40.0^{\circ}\right)\end{array}$ & $\begin{array}{c}59.2 \\
\left(-61.4^{\circ}\right)\end{array}$ & $\begin{array}{c}59.2 \\
\left(-61.4^{\circ}\right)\end{array}$ & $\begin{array}{c}45.4 \\
\left(-40.0^{\circ}\right)\end{array}$ \\
\hline B & $\begin{array}{c}84.6 \\
\left(-200.0^{\circ}\right)\end{array}$ & $\begin{array}{c}45.4 \\
\left(160.0^{\circ}\right)\end{array}$ & $\begin{array}{c}84.6 \\
\left(-200.0^{\circ}\right)\end{array}$ & $\begin{array}{c}59.2 \\
\left(-181.4^{\circ}\right)\end{array}$ & $\begin{array}{c}84.6 \\
\left(-200.0^{\circ}\right)\end{array}$ & $\begin{array}{c}84.6 \\
\left(-200.0^{\circ}\right)\end{array}$ & $\begin{array}{c}45.4 \\
\left(-160.0^{\circ}\right)\end{array}$ & $\begin{array}{c}84.6 \\
\left(-200.0^{\circ}\right)\end{array}$ \\
\hline $\mathrm{C}$ & $\begin{array}{c}45.4 \\
\left(80.0^{\circ}\right)\end{array}$ & $\begin{array}{c}84.6 \\
\left(40.0^{\circ}\right)\end{array}$ & $\begin{array}{c}59.2 \\
\left(58.6^{\circ}\right)\end{array}$ & $\begin{array}{c}84.6 \\
\left(40.0^{\circ}\right)\end{array}$ & $\begin{array}{c}59.2 \\
\left(58.6^{\circ}\right)\end{array}$ & $\begin{array}{c}45.4 \\
\left(80.0^{\circ}\right)\end{array}$ & $\begin{array}{c}84.6 \\
\left(40.0^{\circ}\right)\end{array}$ & $\begin{array}{c}59.2 \\
\left(58.6^{\circ}\right)\end{array}$ \\
\hline \multirow{2}{*}{ - } & \multicolumn{8}{|c|}{ Current Unbalance } \\
\hline & $28.7 \%$ & $26.6 \%$ & $17.1 \%$ & $17.1 \%$ & $26.6 \%$ & $28.7 \%$ & $26.6 \%$ & $26.6 \%$ \\
\hline
\end{tabular}

${ }^{1}$ Phase-to-ground current, in Amperes. Magnitude and angle (between parenthesis).

The contact resistance has been simulated with two different and purely resistive values. For instance, a $40 \Omega$ resistance is a typical value for determining the minimum phase-to-ground short-circuit current for fuse specification and overcurrent protection devices. The $8000 \Omega$ resistance corresponds to a phase-to-ground fault current of approximately $1 \mathrm{~A}$ for a $13.8 \mathrm{kV}$ system.

The proposed method to detect and locate HIFs in primary feeders is applied to several representative cases of high impedance series or shunt faults, which consist of combinations of the following situations:

- Number of opened conductors: 0 to 2;

- Contact or no contact to the ground;

- Contact to the ground on the load-side or the source-side;

- Contact resistance to the ground: $40 \Omega$ or $8000 \Omega$. 


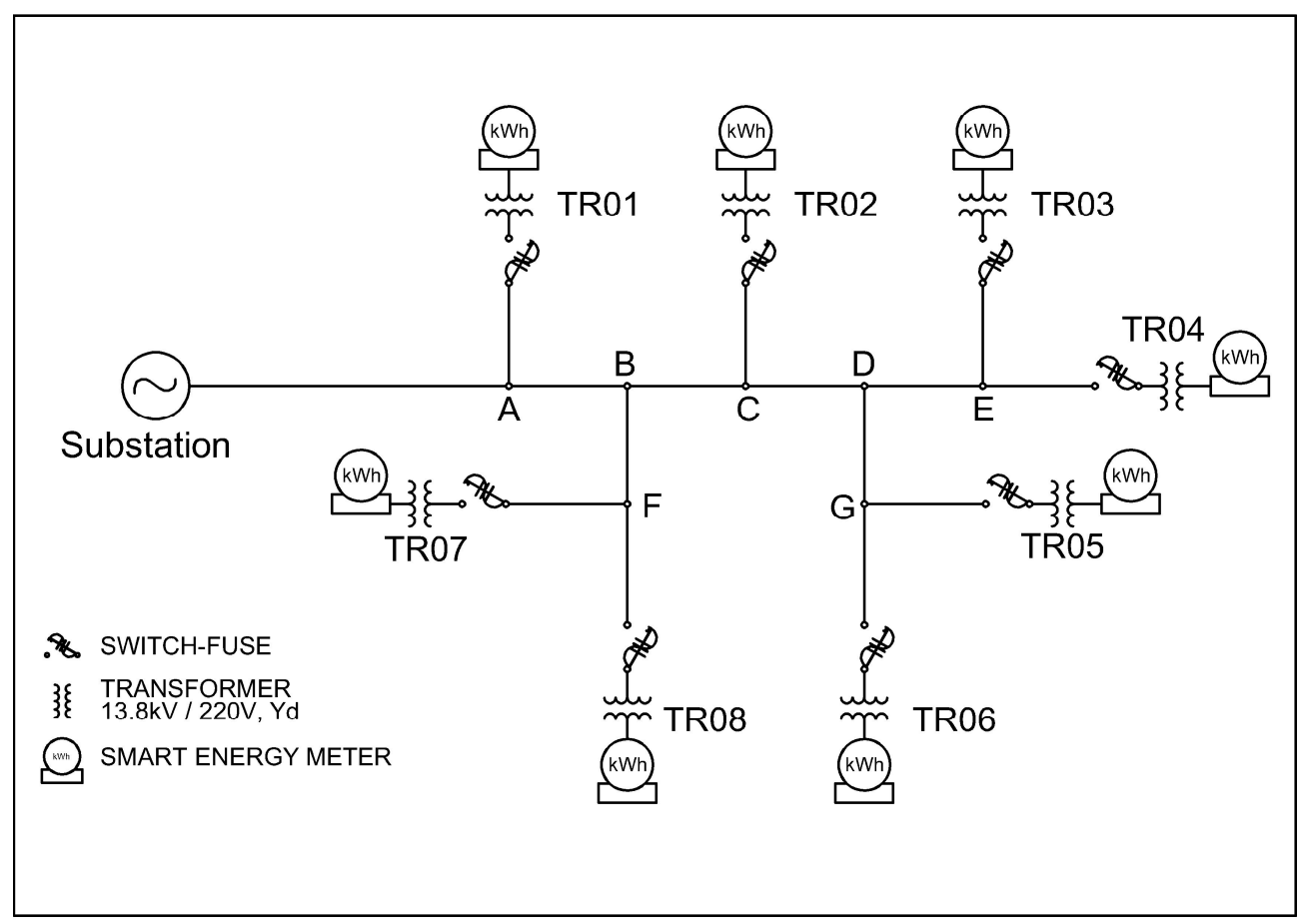

Figure 5. One-line diagram of the test distribution feeder (adapted from [28]).

Each case scenario is modeled, implemented, and simulated on the MATLAB/Simulink (version 9.4-R2018a, The MathWorks, Inc., Natick, MA, USA). To detect a probable HIF and its location, the simulation output is analyzed throughout the steps presented in the flowchart of Figure 4. The simulated fault scenarios are presented in Table 4.

Table 4. Simulated scenarios.

\begin{tabular}{ccccc}
\hline Case & Fault Type $^{\mathbf{1}}$ & Fault Description & Fault Condition & Contact Resistance \\
\hline 1 & (a) & One broken conductor & Hanging in the air & - \\
2 & (b) & One broken conductor & Source-side contact & $40 \Omega$ \\
3 & (b) & One broken conductor & Source-side contact & $8000 \Omega$ \\
4 & (c) & One broken conductor & Load-side contact & $40 \Omega$ \\
5 & (c) & One broken conductor & Load-side contact & $8000 \Omega$ \\
6 & (a) & Two broken conductors & Hanging in the air & - \\
7 & (d) & No broken conductor & Shunt & $40 \Omega$ \\
8 & (d) & No broken conductor & Shunt & $8000 \Omega$ \\
\hline
\end{tabular}

${ }^{1}$ (a) Passive series fault; (b) downed conductor to the source-side; (c) downed conductor to the load-side; and (d) shunt fault.

Moreover, an overhead conductor rupture is similar to a manual opening of a one-phase-switch or a blown fuse, for instance. Therefore, the operator should be previously informed about system sections under maintenance with the purpose of distinguishing them from broken conductor situations. However, the decision of switching a circuit off must take additional aspects into consideration.

\section{Results}

\subsection{System Operating Under Normal Conditions}

The case used as a reference was simulated in a normal condition, with no faults. The loads are set to an unbalance up to $30 \%$, according to Table 3, and transformers are $50 \%$ loaded. The obtained voltage unbalance factors related to each smart meter as a result of the load conditions shown in Table 3 are presented in the column described as case " 0 " in Tables $5-8$. 
Table 5. Faults on section DG—voltage unbalance (results of $K_{\%}$ for normal and fault condition).

\begin{tabular}{|c|c|c|c|c|c|c|c|c|c|}
\hline \multicolumn{10}{|c|}{$\begin{array}{l}\text { Voltage Unbalance Factor-K } \\
\text { Faults on Section DG }\end{array}$} \\
\hline \multirow{3}{*}{$\begin{array}{c}\text { Cases } \\
\text { Meter } \\
\text { Position }\end{array}$} & \multirow{2}{*}{$\begin{array}{c}\text { No Fault } \\
0\end{array}$} & \multicolumn{5}{|c|}{ One Broken Conductor ${ }^{1}$} & \multirow{2}{*}{$\frac{\text { Two }^{2}}{6}$} & \multicolumn{2}{|c|}{ Shunt } \\
\hline & & 1 & 2 & 3 & 4 & 5 & & 7 & 8 \\
\hline & Unb. ${ }^{3}$ & Air & S-40 $\Omega$ & S-8k $\Omega$ & L-40 $\Omega$ & L-8k $\Omega$ & Air & $40 \Omega$ & $8 \mathrm{k} \Omega$ \\
\hline TR01 & 1.16 & 1.18 & 2.08 & 1.18 & 1.18 & 1.18 & 1.15 & 2.08 & 1.16 \\
\hline TR02 & 1.02 & 0.98 & 3.91 & 0.98 & 0.98 & 0.98 & 1.05 & 3.95 & 1.02 \\
\hline TR03 & 0.80 & 0.88 & 4.33 & 0.86 & 0.87 & 0.87 & 0.78 & 4.36 & 0.78 \\
\hline TR04 & 0.70 & 0.67 & 4.57 & 0.66 & 0.67 & 0.67 & 0.74 & 4.61 & 0.69 \\
\hline TR05 & 1.10 & 99.70 & 99.70 & 99.70 & 49.21 & 71.90 & $\mathrm{IND}^{4}$ & 4.96 & 1.07 \\
\hline TR06 & 1.20 & 100.30 & 100.30 & 100.30 & 49.58 & 72.28 & IND & 5.63 & 1.19 \\
\hline TR07 & 1.03 & 1.00 & 2.82 & 1.00 & 1.00 & 1.00 & 1.05 & 2.85 & 1.03 \\
\hline TR08 & 1.10 & 1.14 & 1.82 & 1.13 & 1.14 & 1.14 & 1.10 & 1.83 & 1.09 \\
\hline
\end{tabular}

${ }^{1}$ Contact resistance, L-load-side or S-source-side; ${ }^{2}$ two broken conductors; ${ }^{3}$ unbalanced load, normal condition; 4 indeterminacy.

Table 6. Faults on section DE—voltage unbalance (results of $\mathrm{K}_{\%}$ for normal and fault condition).

\begin{tabular}{|c|c|c|c|c|c|c|c|c|c|}
\hline \multicolumn{10}{|c|}{$\begin{array}{l}\text { Voltage Unbalance Factor } K_{\%} \\
\text { Faults on Section DE }\end{array}$} \\
\hline Cases & No Fault & \multicolumn{5}{|c|}{ One Broken Conductor ${ }^{1}$} & Two $^{2}$ & \multicolumn{2}{|c|}{ Shunt } \\
\hline Meter & 0 & 1 & 2 & 3 & 4 & 5 & 6 & 7 & 8 \\
\hline Position & Unb. ${ }^{3}$ & Air & S-40 $\Omega$ & S-8k $\Omega$ & L-40 $\Omega$ & L-8k $\Omega$ & Air & $40 \Omega$ & $8 \mathrm{k} \Omega$ \\
\hline TR01 & 1.16 & 1.19 & 2.08 & 1.19 & 1.19 & 1.19 & 1.19 & 2.08 & 1.16 \\
\hline TR02 & 1.02 & 0.96 & 3.92 & 0.96 & 0.97 & 0.96 & 0.96 & 3.95 & 1.02 \\
\hline TR03 & 0.80 & 89.82 & 89.82 & 89.82 & 49.50 & 69.33 & IND $^{4}$ & 5.46 & 0.78 \\
\hline TR04 & 0.70 & 89.61 & 89.61 & 89.61 & 49.91 & 69.68 & IND & 5.76 & 0.69 \\
\hline TR05 & 1.10 & 1.16 & 3.84 & 1.14 & 1.16 & 1.16 & 1.16 & 3.85 & 1.08 \\
\hline TR06 & 1.20 & 1.28 & 4.57 & 1.28 & 1.28 & 1.28 & 1.28 & 4.57 & 1.19 \\
\hline TR07 & 1.03 & 0.99 & 2.83 & 0.98 & 0.99 & 0.99 & 0.99 & 2.85 & 1.03 \\
\hline TR08 & 1.10 & 1.14 & 1.84 & 1.13 & 1.14 & 1.14 & 1.14 & 1.83 & 1.09 \\
\hline
\end{tabular}

${ }^{1}$ Contact resistance, L-load-side or S-source-side; ${ }^{2}$ two broken conductors; ${ }^{3}$ unbalanced load, normal condition; 4 indeterminacy.

Table 7. Faults on section CD—voltage unbalance (results of $K_{\%}$ for normal and fault condition).

\begin{tabular}{|c|c|c|c|c|c|c|c|c|c|}
\hline \multicolumn{10}{|c|}{$\begin{array}{c}\text { Voltage Unbalance Factor- }-K_{\%} \\
\text { Faults on Section CD }\end{array}$} \\
\hline \multirow{3}{*}{$\begin{array}{c}\text { Cases } \\
\text { Meter } \\
\text { Position }\end{array}$} & \multirow{2}{*}{$\begin{array}{c}\text { No Fault } \\
0\end{array}$} & \multicolumn{5}{|c|}{ One Broken Conductor ${ }^{1}$} & \multirow{2}{*}{$\begin{array}{c}\text { Two }^{2} \\
6\end{array}$} & \multicolumn{2}{|c|}{ Shunt } \\
\hline & & 1 & 2 & 3 & 4 & 5 & & 7 & 8 \\
\hline & Unb. ${ }^{3}$ & Air & S $-40 \Omega$ & S-8k $\Omega$ & $\mathrm{L}-40 \Omega$ & L-8k $\Omega$ & Air & $40 \Omega$ & $8 \mathrm{k} \Omega$ \\
\hline TR01 & 1.16 & 1.21 & 2.17 & 1.21 & 1.21 & 1.21 & 1.14 & 2.16 & 1.16 \\
\hline TR02 & 1.02 & 0.91 & 4.07 & 0.91 & 0.92 & 0.92 & 1.06 & 4.14 & 1.02 \\
\hline TR03 & 0.80 & 93.61 & 93.61 & 93.61 & 49.61 & 79.95 & $\mathrm{IND}^{4}$ & 4.64 & 0.78 \\
\hline TR04 & 0.70 & 93.26 & 93.26 & 93.26 & 50.02 & 80.03 & IND & 4.88 & 0.69 \\
\hline TR05 & 1.10 & 93.29 & 93.29 & 93.29 & 49.24 & 79.62 & IND & 4.13 & 1.08 \\
\hline TR06 & 1.20 & 93.85 & 93.85 & 93.85 & 49.61 & 80.05 & IND & 4.85 & 1.19 \\
\hline TR07 & 1.03 & 0.96 & 2.92 & 0.95 & 0.96 & 0.96 & 1.06 & 2.98 & 1.03 \\
\hline TR08 & 1.10 & 1.18 & 1.97 & 1.17 & 1.17 & 1.18 & 1.09 & 1.98 & 1.09 \\
\hline
\end{tabular}

${ }^{1}$ Contact resistance, L-load-side or S-source-side; ${ }^{2}$ two broken conductors; ${ }^{3}$ unbalanced load, normal condition;

4 indeterminacy. 
Table 8. Faults on section BC-voltage unbalance (results of $K_{\%}$ for normal and fault condition).

\begin{tabular}{|c|c|c|c|c|c|c|c|c|c|}
\hline \multicolumn{10}{|c|}{$\begin{array}{c}\text { Voltage Unbalance Factor- }-K_{\%} \\
\text { Faults on Section BC }\end{array}$} \\
\hline \multirow{3}{*}{$\begin{array}{c}\text { Cases } \\
\begin{array}{c}\text { Meter } \\
\text { Position }\end{array}\end{array}$} & \multirow{2}{*}{$\begin{array}{c}\text { No Fault } \\
0\end{array}$} & \multicolumn{5}{|c|}{ One Broken Conductor ${ }^{1}$} & \multirow{2}{*}{$\frac{\text { Two }^{2}}{6}$} & \multicolumn{2}{|c|}{ Shunt } \\
\hline & & 1 & 2 & 3 & 4 & 5 & & 7 & 8 \\
\hline & Unb. ${ }^{3}$ & Air & S-40 $\Omega$ & S-8k $\Omega$ & $\mathrm{L}-40 \Omega$ & L-8k $\Omega$ & Air & $40 \Omega$ & $8 \mathrm{k} \Omega$ \\
\hline TR01 & 1.16 & 1.23 & 2.27 & 1.23 & 1.22 & 1.23 & 1.15 & 2.26 & 1.16 \\
\hline TR02 & 1.02 & 90.54 & 90.54 & 90.54 & 50.39 & 80.77 & IND $^{4}$ & 4.36 & 1.02 \\
\hline TR03 & 0.80 & 90.65 & 90.65 & 90.65 & 49.59 & 80.46 & IND & 3.77 & 0.79 \\
\hline TR04 & 0.70 & 90.40 & 90.40 & 90.40 & 50.01 & 80.53 & IND & 3.92 & 0.69 \\
\hline TR05 & 1.10 & 90.33 & 90.33 & 90.33 & 49.23 & 80.13 & IND & 3.25 & 1.08 \\
\hline TR06 & 1.20 & 90.86 & 90.86 & 90.86 & 49.60 & 80.56 & IND & 4.03 & 1.19 \\
\hline TR07 & 1.03 & 0.93 & 3.06 & 0.93 & 0.94 & 0.93 & 1.05 & 3.12 & 1.03 \\
\hline TR08 & 1.10 & 1.20 & 2.14 & 1.18 & 1.19 & 1.19 & 1.08 & 2.15 & 1.09 \\
\hline
\end{tabular}

${ }^{1}$ Contact resistance, L-load-side or S—-source-side; ${ }^{2}$ two broken conductors; ${ }^{3}$ unbalanced load, normal condition;

4 indeterminacy.

\subsection{System Operating Under Fault Conditions}

Faults in four sections of the test feeder were selected as the most representative results. An important parameter considered for choosing these sections was the distance from the fault point to the substation; the further from the source, the harder to detect and locate the fault. The obtained results are presented and analyzed in the following subsections.

\subsubsection{Faults on Section DG}

Figure 6 describes the test feeder, and the fault section is highlighted in red, while the affected branches and the downstream the fault are shown in yellow.

Table 5 presents the voltage unbalance factors $K_{\%}$ obtained from the simulations, where $K_{\%}$ above $30 \%$ are highlighted in red. The cases with broken conductors (cases 1 to 6 ) show high unbalanced voltages on the meters located under transformers TR05 and TR06. The section DG is the branch immediately upstream of transformers TR05 and TR06, which correctly indicates section DG as the fault location.

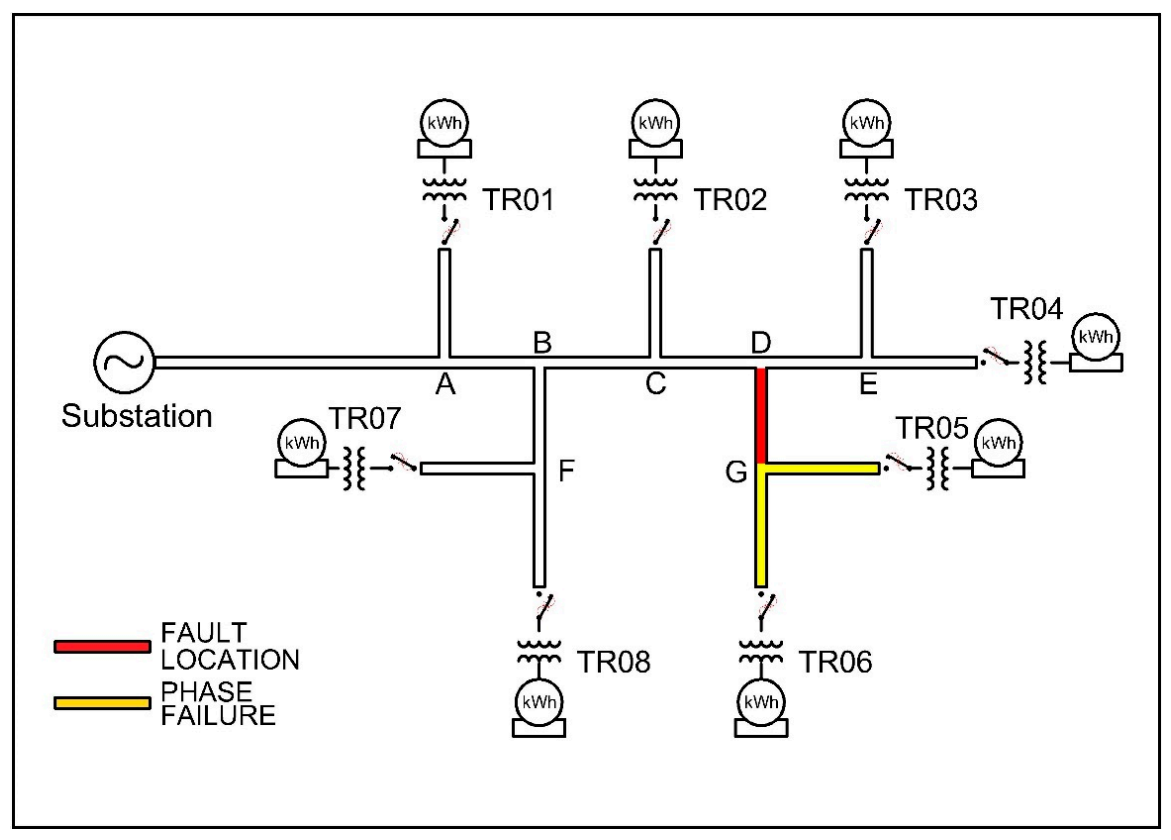

Figure 6. Faults on section DG. 
The measurements for shunt faults (cases 7 and 8 ) are inconclusive to determine the presence of a fault. Note that sections not affected by the fault have a factor $K_{\%}$ below $5 \%$. Downed conductors to the load-side usually have a voltage unbalance of around $50 \%$. In this case, the minimum factor $K_{\%}$ has been reached in case 4 of TR05 (49.21\%). Indeterminacy (IND) is a situation where the unbalance factor cannot be calculated due to the loss of two or more phases.

\subsubsection{Faults on Section DE}

Figure 7 shows the faulted section DE highlighted in red, while the affected branches, downstream to the fault, are shown in yellow.

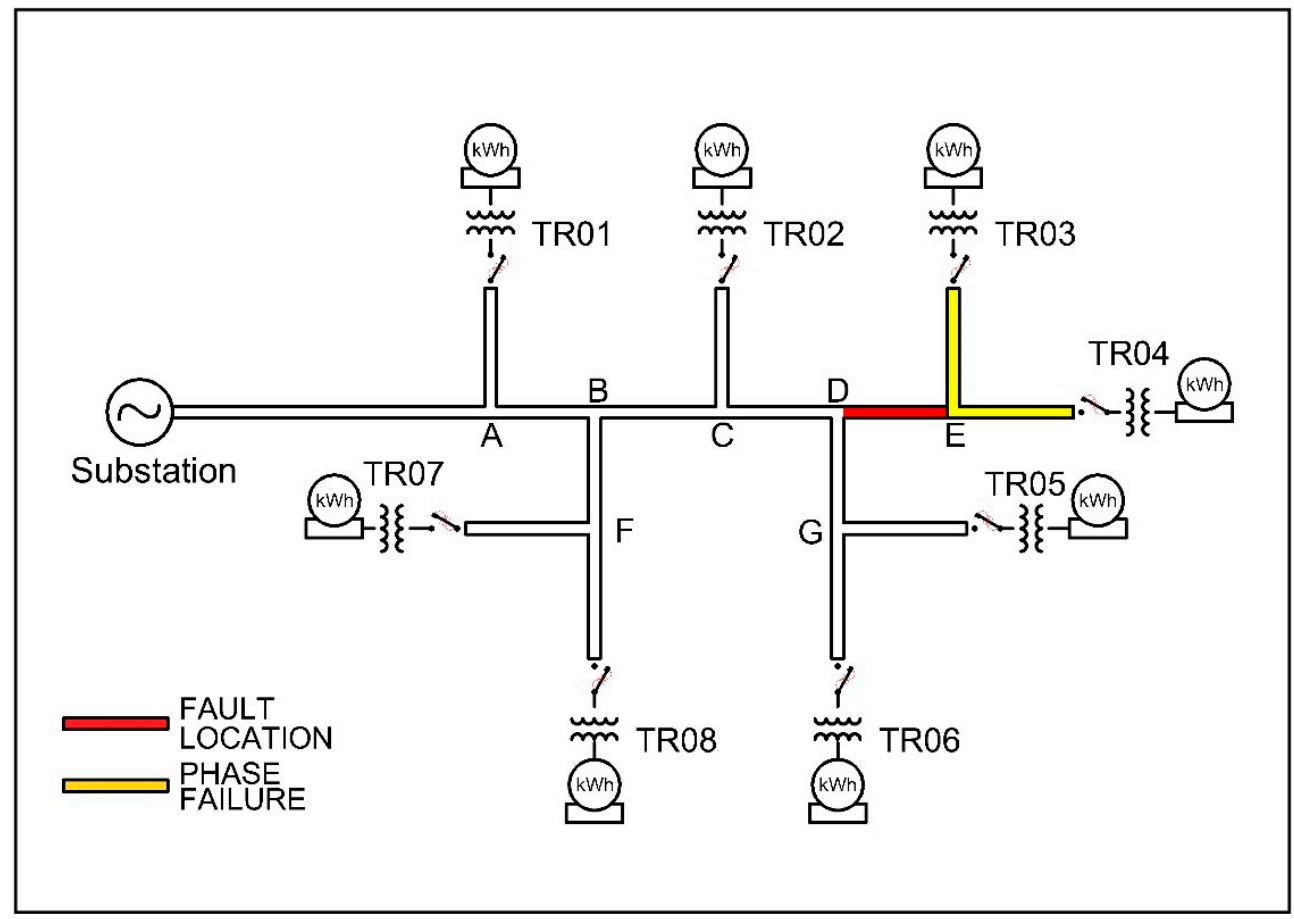

Figure 7. Faults on section DE.

Table 6 presents the voltage unbalance factor $K_{\%}$ obtained from the simulations, where unbalances above $30 \%$ are highlighted in red.

The cases with broken conductors (cases 1 to 6) show high unbalanced voltages on the meters located under transformers TR03 and TR04 only. The section DE is the branch immediately upstream of transformers TR03 and TR04. Therefore, the algorithm correctly indicates section DE as the fault location. The results for shunt faults (cases 7 and 8 ) are inconclusive to determine the presence of a fault. Factor $K \%$ is also below $5 \%$ in non-faulty sections.

\subsubsection{Faults on Section CD}

Figure 8 shows the faulted section CD highlighted in red, while the affected branches, downstream the fault, are shown in yellow.

Table 7 presents the voltage unbalance factors $K_{\%}$ obtained from the simulations, where values above $30 \%$ are highlighted in red. The cases with broken conductors (cases 1 to 6 ) show high unbalanced voltages on the meters located under transformers TR03, TR04, TR05, and TR06. The section CD is the branch immediately upstream of transformers TR03, TR04, TR05, and TR06, and the algorithm correctly indicates section $\mathrm{CD}$ as the fault location. The measurements for shunt faults (cases 7 and 8 ) are inconclusive for determining the presence of a fault. 


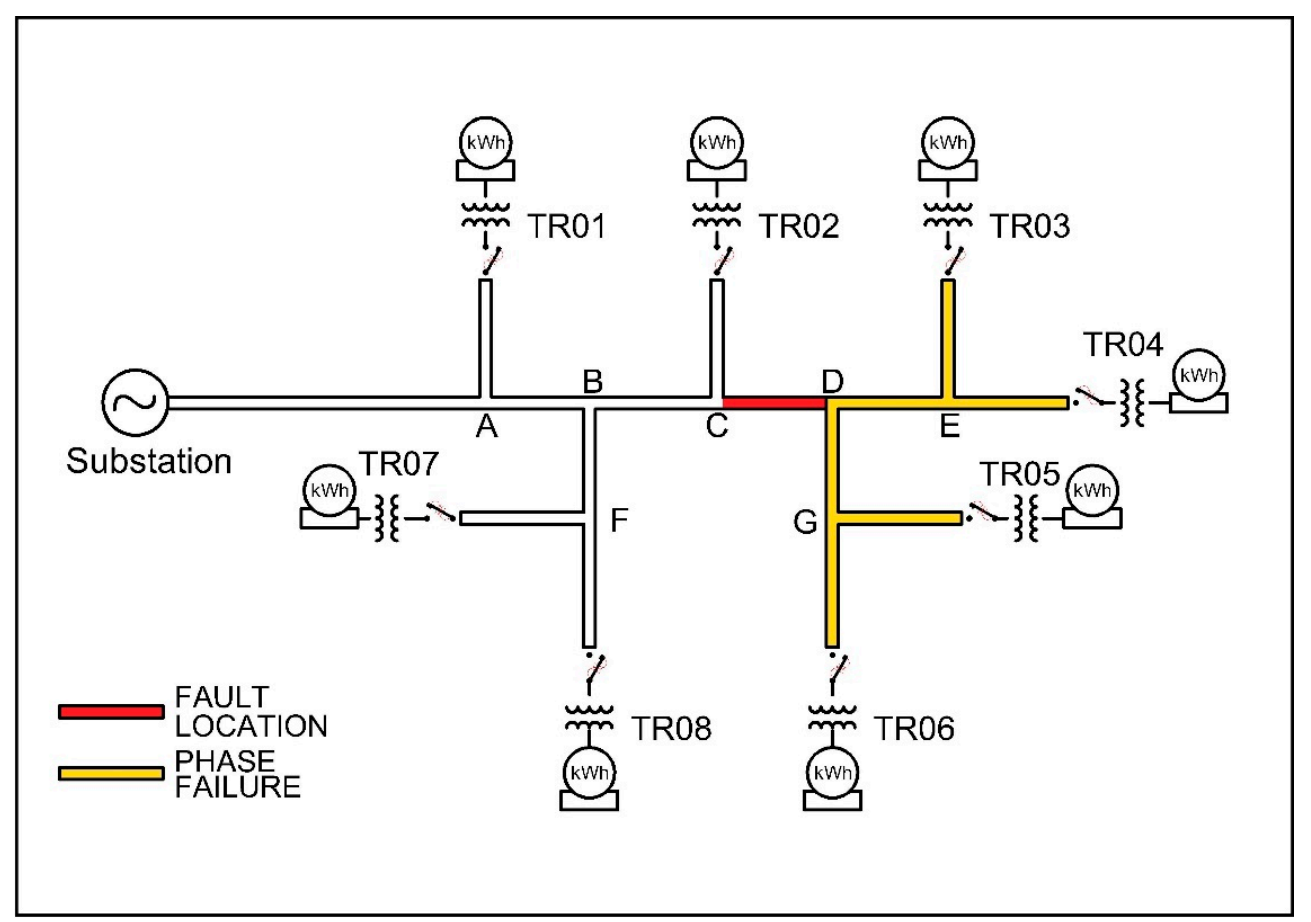

Figure 8. Faults on section CD.

\subsubsection{Faults on Section BC}

Figure 9 shows the faulted section BC highlighted in red, while the affected branches, downstream of the fault, are shown in yellow.

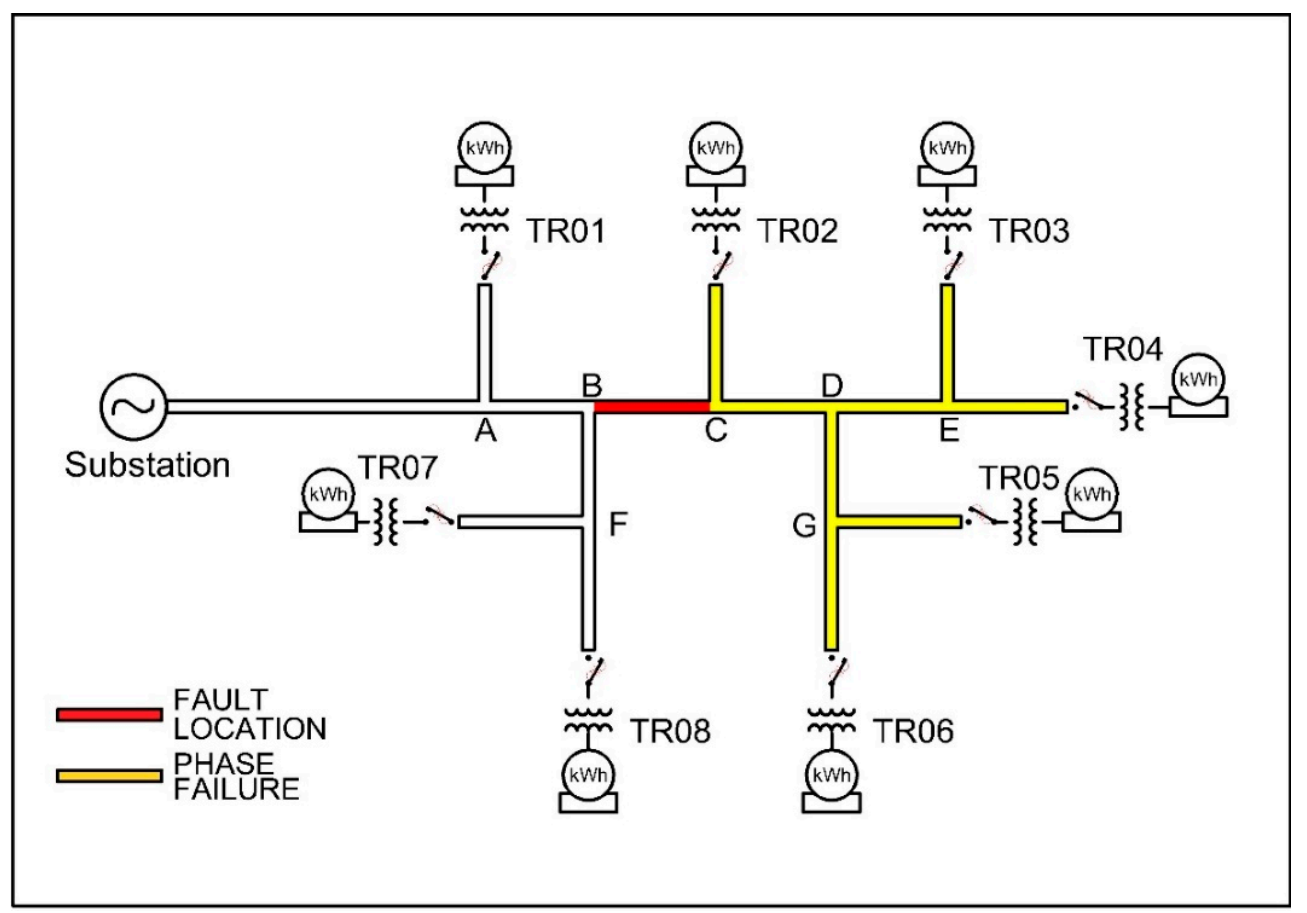

Figure 9. Faults on section BC.

Table 8 presents the voltage unbalance factors $K_{\%}$ obtained from the simulations, where values above $30 \%$ are highlighted in red.

The cases with broken conductors (cases 1 to 6 ) show high unbalanced voltages on the meters located under transformers TR02, TR03, TR04, TR05, and TR06. The section BC is the branch 
immediately upstream from transformers TR02, TR03, TR04, TR05, and TR06. The algorithm correctly indicates section BC as the fault location. The measurements for shunt faults (cases 7 and 8) are inconclusive to determine the presence of a fault.

\subsection{Summary of Results}

Table 9 summarizes the obtained results from the application of the proposed method on simulations. All scenarios for high impedance series faults were identified and located, even using an undetermined unbalance factor for two broken conductors. However, shunt faults were not identified by the proposed method, and no false positives emerged in the results.

Previous papers also presented difficulties in locating high impedance shunt faults. In Reference [24], the detection of open conductors using field sensors installed along the feeder is proposed, which would not be a cost-effective implementation. In [4,25-27], techniques based on the voltage drop and feeder monitoring are used to detect specific HIFs with downed conductors; however, shunt faults were not mentioned.

Table 9. Summary of HIF detection and location.

\begin{tabular}{|c|c|c|c|c|c|}
\hline & \multirow{2}{*}{ Case } & \multicolumn{4}{|c|}{ Fault Detected and Located Correctly? } \\
\hline & & $\mathrm{DG}^{1}$ & DE & CD & BC \\
\hline 1 & One broken conductor, air ${ }^{2}$ & YES & YES & YES & YES \\
\hline 2 & One broken conductor, $\mathrm{S}^{3}, 40 \Omega$ & YES & YES & YES & YES \\
\hline 3 & One broken conductor, $\mathrm{S}, 8 \mathrm{k} \Omega$ & YES & YES & YES & YES \\
\hline 4 & One broken conductor, L, $40 \Omega$ & YES & YES & YES & YES \\
\hline 5 & One broken conductor, $\mathrm{L}, 8 \mathrm{k} \Omega$ & YES & YES & YES & YES \\
\hline 6 & Two broken conductors, air & $\mathrm{IND}^{4}$ & IND & IND & IND \\
\hline 7 & Shunt, $40 \Omega$ & NO & $\mathrm{NO}$ & $\mathrm{NO}$ & $\mathrm{NO}$ \\
\hline 8 & Shunt, $8 \mathrm{k} \Omega$ & NO & $\mathrm{NO}$ & $\mathrm{NO}$ & $\mathrm{NO}$ \\
\hline
\end{tabular}

\section{Conclusions}

A voltage-based approach to detect and locate the HIFs in distribution systems using smart meters was presented. The method implies the implementation of voltage unbalance calculations into smart meters and the use of an algorithm at an operator level to analyze the incoming information from the smart meters and indicate the presence and probable location of a HIF. This method is not intended for direct tripping, but, instead, it may assist the grid operator in the decision-making process in a possible HIF scenario.

According to the obtained results, the proposed approach was efficient to detect series faults with broken conductors and locate the exact branch where it occurs. In the case of two or three broken conductors, although the calculation of voltage unbalance is undetermined, if the proposed algorithm is applied considering the indeterminacies as unbalanced results, it may lead to locating the fault correctly. Finally, for shunt HIF situations, the method has not been able to locate the fault satisfactorily. Additionally, shunt faults usually inflict difficulties for other detection methodologies.

It is worth mentioning that HIF and blown fuses present difficulties to be found in distribution networks and, consequently, provide a fast repair. The methodology presented in this work is useful and efficient in both situations. Considering that the necessary infrastructure implementation is directly related to the use of smart meters and a software of low complexity at operation level, the method is cost-effective, and the installation of a one smart meter at the LV side of each transformer may be sufficient to lead to the detection and location of the faulted branch in most situations. It presents a cost-effective implementation for measurement and software infrastructure and represents a reduction of public safety hazards, property damage, or human losses, as well as power outage-related losses. 
An important aspect observed from the results is that the open conductor condition was predominant for the success of the detection and location method discussed, regardless of the simulated fault resistance condition: $40 \Omega, 8 \mathrm{k} \Omega$, or a conductor suspended in the air. As the obtained voltage unbalance values were substantial for the cases with open conductors, it is expected that they would overcome the eventual transitory effects caused by arc occurrence with intermittent behavior, which were not considered in the simulations. Nevertheless, the authors observe that the influence of transitory events on the voltage measurements should be the focus of future investigations.

The complexity of large distribution networks and big data issues are two factors that need more computational intelligence involved. New forms to measure signals, process signals, and new techniques can be expected in the future, especially using computational intelligence in smart meters. The implementation of robust geolocation is also interesting to improve location precision. Therefore, the authors recognize the importance of computational intelligence applied to power distribution systems, considering it for further investigation.

Author Contributions: Conceptualization, F.L.V., J.M.C.F., and M.P.L.; formal analysis, F.L.V., P.H.M.S., and R.C.L.; investigation, F.L.V. and P.H.M.S.; methodology, F.L.V., J.M.C.F., and M.P.L.; software, F.L.V., and M.P.L.; supervision, J.M.C.F., and R.C.L.; validation, F.L.V. and P.H.M.S.; writing-original draft, F.L.V. and P.H.M.S.; writing —review and editing, F.L.V., P.H.M.S., J.M.C.F., and R.C.L.

Funding: The authors gratefully acknowledge the financial support in part of CAPES-Coordenação de Aperfeiçoamento de Pessoal de Nível Superior, Brasil, Finance Code 001 through a scholarship to FLV.

Acknowledgments: The authors thank the support of CNPq-Conselho Nacional de Desenvolvimento Científico e Tecnológico, Brasil, INERGE, Instituto Nacional de Energia Elétrica, FAPEMIG—Fundação de Amparo à Pesquisa no Estado de Minas Gerais, and the educational support from UNIFEI.

Conflicts of Interest: The authors declare no conflict of interest.

\section{References}

1. Santos, W.C.; Lopes, F.V.; Brito, N.S.D.; Souza, B.A. High-Impedance Fault Identification on Distribution Networks. IEEE Trans. Power Deliv. 2017, 32, 23-32. [CrossRef]

2. Hou, D. Detection of High-Impedance Faults in Power Distribution Systems. In Proceedings of the IEEE 2007 Power Systems Conference: Advanced Metering, Protection, Control, Communication, and Distributed Resources, Clemson, SC, USA, 13-16 March 2007; pp. 85-95. [CrossRef]

3. High Impedance Fault Detection Technology. Available online: http:/grouper.ieee.org/groups/td/dist/ documents/highz.pdf (accessed on 6 March 2019).

4. Garcia-Santander, L.; Bastard, P.; Petit, M.; Gal, I.; Lopez, E.; Opazo, H. Down-Conductor Fault Detection and Location via a Voltage Based Method for Radial Distribution Networks. IEE Proc. Gener. Transm. Distrib. 2005, 152, 180-184. [CrossRef]

5. Ghaderi, A.; Ginn, H.L.; Mohammadpour, H.A. High Impedance Fault Detection: A Review. Electr. Power Syst. Res. 2017, 143, 376-388. [CrossRef]

6. Torres, V.; Guardado, J.L.; Ruiz, H.F.; Maximov, S. Modeling and Detection of High Impedance Faults. Int. J. Electr. Power Energy Syst. 2014, 61, 163-172. [CrossRef]

7. Mitolo, M.; Musca, R.; Zizzo, G. A Cost-Effective Solution for Clearing High-Impedance Ground Faults in Overhead Low-Voltage Lines. IEEE Trans. Ind. Appl. 2019, 55, 1208-1213. [CrossRef]

8. Emanuel, A.E.; Cyganski, D.; Orr, J.A.; Shiller, S.; Gulachenski, E.M. High Impedance Fault Arcing on Sandy Soil in 15 KV Distribution Feeders: Contributions to the Evaluation of the Low Frequency Spectrum. IEEE Trans. Power Deliv. 1990, 5, 676-686. [CrossRef]

9. Soheili, A.; Sadeh, J.; Bakhshi, R. Modified FFT Based High Impedance Fault Detection Technique Considering Distribution Non-Linear Loads: Simulation and Experimental Data Analysis. Int. J. Electr. Power Energy Syst. 2018, 94, 124-140. [CrossRef]

10. Gadanayak, D.A.; Mallick, R.K. Interharmonics Based High Impedance Fault Detection in Distribution Systems Using Maximum Overlap Wavelet Packet Transform and a Modified Empirical Mode Decomposition. Int. J. Electr. Power Energy Syst. 2019, 112, 282-293. [CrossRef] 
11. Elkalashy, N.I.; Lehtonen, M.; Darwish, H.A.; Taalab, A.-M.I.; Izzularab, M.A. A Novel Selectivity Technique for High Impedance Arcing Fault Detection in Compensated MV Networks. Eur. Trans. Electr. Power 2008, 18, 344-363. [CrossRef]

12. Farias, P.E.; de Morais, A.P.; Rossini, J.P.; Cardoso, G., Jr. Non-Linear High Impedance Fault Distance Estimation in Power Distribution Systems: A Continually Online-Trained Neural Network Approach. Electr. Power Syst. Res. 2018, 157, 20-28. [CrossRef]

13. Vantuch, T.; Prílepok, M.; Fulneček, J.; Hrbáč, R.; Mišák, S. Towards the Text Compression Based Feature Extraction in High Impedance Fault Detection. Energies 2019, 12, 2148. [CrossRef]

14. Almalki, M.; Hatziadoniu, C. Classification of Many Abnormal Events in Radial Distribution Feeders Using the Complex Morlet Wavelet and Decision Trees. Energies 2018, 11, 546. [CrossRef]

15. Baqui, I.; Zamora, I.; Mazón, J.; Buigues, G. High Impedance Fault Detection Methodology Using Wavelet Transform and Artificial Neural Networks. Electr. Power Syst. Res. 2011, 81, 1325-1333. [CrossRef]

16. Silva, S.; Costa, P.; Gouvea, M.; Lacerda, A.; Alves, F.; Leite, D. High Impedance Fault Detection in Power Distribution Systems Using Wavelet Transform and Evolving Neural Network. Electr. Power Syst. Res. 2018, 154, 474-483. [CrossRef]

17. Hubana, T.; Saric, M.; Avdaković, S. Approach for Identification and Classification of HIFs in Medium Voltage Distribution Networks. IET Gener. Transm. Distrib. 2018, 12, 1145-1152. [CrossRef]

18. Veerasamy, V.; Abdul Wahab, N.; Ramachandran, R.; Mansoor, M.; Thirumeni, M.; Lutfi Othman, M. High Impedance Fault Detection in Medium Voltage Distribution Network Using Discrete Wavelet Transform and Adaptive Neuro-Fuzzy Inference System. Energies 2018, 11, 3330. [CrossRef]

19. Von Meier, A.; Stewart, E.; McEachern, A.; Andersen, M.; Mehrmanesh, L. Precision Micro-Synchrophasors for Distribution Systems: A Summary of Applications. IEEE Trans. Smart Grid 2017, 8, 2926-2936. [CrossRef]

20. Jamali, S.; Bahmanyar, A.; Bompard, E. Fault Location Method for Distribution Networks Using Smart Meters. Meas. J. Int. Meas. Confed. 2017, 102, 150-157. [CrossRef]

21. Chakraborty, S.; Das, S. Application of Smart Meters in High Impedance Fault Detection on Distribution Systems. IEEE Trans. Smart Grid 2019, 10, 3465-3473. [CrossRef]

22. Radhakrishnan, A.; Das, S. Protection Functionalities in Smart Meters to Enhance Distribution System Protection. In Proceedings of the 2018 IEEE Innovative Smart Grid Technologies-Asia (ISGT Asia), Singapore, 22-25 May 2018; pp. 1038-1043. [CrossRef]

23. Kezunovic, M. Smart Fault Location for Smart Grids. IEEE Trans. Smart Grid 2011, 2, 11-22. [CrossRef]

24. Senger, E.C.; Kaiser, W.; Santos, J.C.; Burt, P.M.S.; Malagodi, C.V.S. Broken Conductors Protection System Using Carrier Communication. IEEE Trans. Power Deliv. 2000, 15, 525-530. [CrossRef]

25. Thomas, M.S.; Bhaskar, N.; Prakash, A. Voltage Based Detection Method for High Impedance Fault in a Distribution System. J. Inst. Eng. Ser. B 2016, 97, 413-423. [CrossRef]

26. Al-Ghannam, S.H.; Khan, Y.; Ahmad, U.; Malik, N.H.; Al-Arainy, A.A.; Al-Shahrani, B.S. Development of Open (Broken) Conductor Detection System for High Resistivity Areas. In Proceedings of the IEEE2017 Saudi Arabia Smart Grid (SASG), Jeddah, Saudi Arabia, 12-14 December 2017; pp. 1-8. [CrossRef]

27. Abhijith, U.P.; Akhil, K.; Amal, K.; Salam, A.; Shabeeb Backer, T.K.; Sangeetha, K. High Impedance Fault Detectors for Radial Secondary Distributors. In Proceedings of the IEEE 2015 International Conference on Control Communication \& Computing India (ICCC), Trivandrum, India, 19-21 November 2015; pp. 314-318. [CrossRef]

28. Vieira, F.L.; Carvalho Filho, J.M.; Silveira, P.M.; Guerrero, C.A.V.; Leite, M.P. High Impedance Fault Detection and Location in Distribution Networks Using Smart Meters. In Proceedings of the IEEE 18th International Conference on Harmonics and Quality of Power (ICHQP), Ljubljana, Slovenia, 13-16 May 2018; pp. 1-6. [CrossRef]

29. International Electrotechnical Commission (IEC). Standard 61000-4-30: Testing and Measurement Techniques_Power Quality Measurement Methods, 3rd ed.; IEC: Geneva, Switzerland, 2015.

30. Olczykowski, Z.; Wasowski, A. Methods of Voltage Unbalance Estimation in Electric Power Networks. Electr. Power Qual. Util. 2006, 12, 71-76.

31. Garcia, D.C.; Filho, A.L.F.; Oliveira, M.A.G.; Fernandes, O.A.; do Nascimento, F.A. Voltage Unbalance Numerical Evaluation and Minimization. Electr. Power Syst. Res. 2009, 79, 1441-1445. [CrossRef] 
32. Seiphetlho, T.E.; Rens, A.P.J. On the Assessment of Voltage Unbalance. In Proceedings of the IEEE 14th International Conference on Harmonics and Quality of Power-ICHQP 2010, Bergamo, Italy, 26-29 September 2010; pp. 1-6. [CrossRef]

33. Arghavani, H.; Peyravi, M. Unbalanced Current-Based Tariff. CIRED Open Access Proc. J. 2017, $2017,883-887$. [CrossRef]

34. IEEE Power \& Energy Society. IEEE Std 1159: Recommended Practice for Monitoring Electric Power Quality; IEEE: New York, NY, USA, 2009. [CrossRef]

35. CENELEC TC 8X. Standard EN 50160: Voltage Characteristics of Electricity Supplied by Public Electricity Networks; CENELEC: Brussels, Belgium, 2010. 